\title{
LA CRÍTICA DE JUAN LUIS VIVES A LOS PSEUDO-DIALÉCTICOS
}

\author{
Jorge M. Ayala \\ Universidad de Zaragoza
}

\section{RESUMEN}

En este trabajo se estudia una faceta del humanismo de Juan Luis Vives: su crítica a la lógica nominalista. Para el filósofo español, Ia gramática y la retórica eran inseparables de la dialéctica. Posiblemente, Juan Luis Vives no entendió bien el sentido de la lógica nominalista; sin embargo, su contribución a la lógica humanista fue importante.

\begin{abstract}
Juan Luis Vives: Humanistic Logic versus Nominalistc Logic. In this work we study an aspect of the Humanism of Juan Luis Vives: his critique to the Nominalistic Logic. According to the Spanish philosopher, Grammar and Rhetoric were not separable from Dialectic. Perhaps Juan Luis Vives did not understand very well the sense of the Nominalistic Logic. Nevertheles his contribution to the humanictic Logic was quite considerable.
\end{abstract}

\section{JUAN LUIS VIVES, ENTRE LA NOSTALGIA Y EL EXILIO}

Juan Luis Vives vivió unido afectivamente a la tierra en que nació, Valencia, como se ama a la persona querida, es decir, sin poder dejar de quererla. En sus libros y en sus cartas añadía a su nombre y apellido el adjetivo «valentinus», como un segundo apellido. Vives comenzó su andadura europea como emigrante, una actitud típicamente renacentista que reflejaba la inquietud intelectual de la época. Los grandes espíritus aprendían viajando. Posiblemente, la inquietud intelectual del joven Vives iba acompañada también de cierta rebeldía e incluso de oculto temor. A punto estuvo en una ocasión, y éstas nunca le faltaron, de volver a España. ${ }^{1}$ No

1 «Mañana parto de Brujas para Inglaterra, donde saludaré a Moro de tu parte con todo cariño, como corresponde a vuestra común amistad; de allí, a España: pero por mar, pues por tierra apenas puede uno vivir en tiempos tan calamitosos. Lo he retrasado hasta ahora por si brillaba alguna esperanza desde España». Cfr. José Jiménez Delgado, Epistolario de Luis Vives (Luis Vives a Cranevelt, 10 de Mayo de 1523), E. Nacional, Madrid, 1978, p. 314 . 
sabemos cuál hubiera sido su reacción ante la realidad española. Lo que sí sabemos con certeza es que Vives prefirió vivir para siempre en los Países Bajos como un desterrado voluntario. En sus cartas deja ver que su imagen de España y de los españoles no había mejorado de cuando salió de Valencia; más aún, Vives creía que, en algunos aspectos, había empeorado desde que él la dejó.

Desde su casa de Brujas, Luis Vives podía hacer una crítica severa de los vicios que, a su juicio, tanto perjudicaban a España para convertirse en un país culto. Por fortuna, en aquellos momentos España era una nación suficientemente fuerte como para saber encajar las críticas sin peligro de caer en el desánimo o en la venganza. Hay muchos escritores españoles contemporáneos de Juan Luis Vives (Vitoria, Sepúlveda, Guevara, Garcilaso, etc.) cuyo patriotismo, de ordinario más conformista y gritador, no era menor que el de Vives. Pero ninguno, ni siquiera un pacifista como en ocasiones es Antonio de Guevara, supo compaginar el amor a la patria y el compromiso respecto de ella, con una visión tan objetiva y serena como la que constantemente resplandece en la obra de Luis Vives. ${ }^{2}$

Vives vivió en Brujas como si estuviera en su Valencia. Su esposa, Margarita Valldaura, hija de valencianos, realizó ese milagro permanente de que Vives sintiera junto a ella el calor del hogar que dejó en la ciudad del Turia:

«Tengo a Brujas la misma inclinación que a mi Valencia; y no la nombro con otra voz que la de patria mía, como a la otra patria, porque hace catorce años que habito en ella; y cuando en este tiempo he tenido, a veces, que dejarla, he vuelto siempre a ella como si volviese a la tierra en que nací». ${ }^{3}$

Pero, además de valenciano («valentinus») Juan Luis Vives era español («Hispanus»), miembro de una comunidad política y cultural de alcance universal. El amor que sentía por su España le llevó a criticar su «barbarie», es decir, su falta de cultura clásica y la rudeza de los métodos de enseñanza empleados en las escuelas.

Durante la primera mitad del siglo XVI hubo en España un número considerable de humanistas. Pero eso no bastó para que el Humanismo se convirtiera en un movimiento colectivo y dinamizador de la vida intelectual y religiosa de España. Aquí seguían escaseando los buenos maestros, los libros, las imprentas y las escuelas. Así se desahogaba Luis Vives en una carta a Erasmo:

«... Con que también nuestros españoles se interesan por tus obras; es la noticia más grata que he recibido desde hace mucho tiempo. Espero que, si se acostumbran a esa lectura y a otras semejantes, se suavicen y se despojen de ciertas concepciones bárbaras de la vida. Concepciones de que están imbricados estos espíritus penetrantes pero

2 Gregorio Marañón. Españoles fuera de España. Madrid, Espasa-Calpe, 1948. Luis Vives (Un español fuera de España), Madrid. Espasa-Calpe: 1942.

3 Ibid.: p. 102. Juan Luis Vives, Del socorro de los pobres. Dedicatoria a los Burgomaestres y al senado de Brujas, 1525 . 
ignaros en las humanidades, y que se transmiten los unos a los otros como de mano en mano».

Al depender España y los Países Bajos de un mismo Soberano, la comunicación entre ambos terrorios resultaba enriquecedora en el orden cultural. Flandes era una región privilegiada en lo cultural; un foco de atracción para los estudiantes europeos. Discípulos de Vives en Flandes fueron los españoles Honorato Juan, Diego Gracián de Alderete, Pedro Juan Oliver, Fernando Ruiz de Villegas, Pedro de Maluenda y Antonio Bergés. ${ }^{5}$

Sin embargo, la vía de penetración de Vives en España no se debió ni a sus discípulos ni a los influyentes amigos que tenía en la corte imperial, sino a su relación con Erasmo, cuyos escritos gozaban de gran prestigio en los círculos religiosos y universitarios de España. Para los lectores españoles, ambos humanistas compartían los mismos ideales religiosos, filosóficos, lingüísticos y educativos; por eso, sus nombres andaban siempre juntos. Es verdad que en la práctica no fue así, porque entre ambos se produjo un distanciamiento ideológico y afectivo. ${ }^{6}$

«Erasmo es holandés, escribe José Luis Abellán, pero el erasmismo es español», ${ }^{7}$ porque en ningún país, como en España, los escritos de Erasmo dieron lugar a un movimiento religioso con derivaciones múltiples: culturales, filosóficas y políticas. El erasmismo abarca aproximadamente la primera mitad del siglo XVI. Ahora bien, «Vives es la gran figura del erasmismo español». ${ }^{8}$ Esto explica que los nombres de Erasmo y Vives andaran siempre juntos en los círculos de humanistas. ${ }^{9}$

La incidencia de los escritos de Vives en la España del XVI no fue tan amplia ni tan directa como la que tuvieron los escritos de Erasmo. El mismo Vives era consciente ello:

«... pues no creo tener envidiosos, sobre todo en España, por muchas razones. La primera, porque no vivo allí; la segunda, porque allí leen poco mis obras, menos las

4 Cfr. José Jiménez Delgado, o.c.: p. 368.

5 Juan Luis Vives en su Diálogo XX («El juego de naipes y las Leyes del juego») introduce como interlocutores los nombres de otros españoles: Valladaura. Castillo, Tamayo, Manrique, Lupiano. Cfr. Obras Completas.

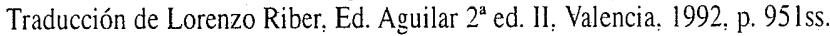

6 La Universidad de.Alcalá de Henares conoció a Vives a través de su amigo Juan de Vergara. «El juicio de este sabio suscitó en nosotros tal opinión de ti, cual no podría satisfacerlo sino un sujeto tan sumamamente docto y del todo semejante al mismo Antonio (Nebrija)». Carta de la Universidad de Alcalá a Juan Luis Vives Cf. José Jiménez Delgado, o.c., p. 245. Acerca de las relaciones de Vives con Erasmo, cfr. Carlos G. Noreña. Juan Luis Vives, Ed. Paulinas, Madrid, 1978, p.163 ss.

7 José Luis Abellán, El erasmismo español, Madrid, Espasa-Calpe, 1982, p.3.

8 Ibid., p. 147. Cfr. «El erasmismo de Luis Vives» en Erasmus in Hispania, Vives in Belgio (Acta Colloquii Brugensis 23-26 IX 1985). Peeters, Lovaina: 1986.

9 Son numerosos los testimonios sobre la mutua estima que se tenían ambos humanistas y sobre la colaboración en algunos trabajos. «Está entre nosotros Luis Vives, el valenciano que no pasa de veintiseis años, pero muy versado ya en todas las ramas de la filosofía, y que ha progresado tanto en las bellas letras, en la elocuencia, en la facilidad de hablar y de escribir: que apenas encuentro a nadie con quien compararlo...» (Carta de Erasmo a Juan de la Parra: médico y preceptor del Príncipe Fernando) Cf. José Jiménez Delgado, o.c., p. 145. 
entienden, menor aun las compran o se preocupan de ellas, dada la frialdad de nuestros compatriotas por el afán de las letras». ${ }^{10}$

Las obras de Vives publicadas en España a lo largo del siglo XVI y XVII fueron: Exercitatio linguae latinae, De conscribendis epistolis, Introductio ad Sapientiam, De Institutione feminae christiana, Preces et Meditationes generales. Es decir, en España se editaron las obras de carácter moral, pedagógico y filológico, pero no las obras filosóficas, aunque es de suponer que éstas (De Anima et vita y De disciplinis) estarían presentes en las bibliotecas de las Universidades o en posesión de los eruditos. Resulta irónico, escribe Enrique González, que la noticia más antigua acerca de un escrito de Vives en España proceda de la Inquisición. El año 1524, en la subasta de bienes que siguió a la ejecución del padre de Luis Vives, apareció una caja de libros «intitulados Joannes Ludovici», que habían sido consignados a un librero para su venta. Oscilarían entre 58 y 88 volúmenes.

\section{LA LÓGICA NOMINALISTA ES INTRODUCIDA EN ALCALÁ Y SALAMANCA}

En la primera mitad del siglo XVI, la España renacentista no había asimilado aún el humanismo filosófico. La modernización filosófica llevada a cabo por las Universidades de Salamanca y de Alcalá de Henares había consistido en la incorporación de la lógica «terminista» que se enseñaba en París, cuando en esta Universidad ya estaba en franco declive o superada por la lógica humanista. "Los introductores de lógica nominal en España fueron profesores españoles que habían estudiado o enseñado en los Colegios Universitarios de París. Algunos de estos profesores habían sido maestros de Luis Vives:

«la mayor parte de la culpa de estos sabios en èl tema que nos ocupa la hacen recaer sobre los españoles que allí viven; pues como son hombres que no se dejan arrollar, defienden la fortaleza de la ignorancia con toda energía y hombres de gran talento, como también son y salen con bien en cualquier cosa que se propongan, se entregan a estas chifladuras y en ellas llegan a ser eminentes».12

Cuenta Erasmo que, mientras Vives fue alumno del Colegio parisino de Monteagudo (1509-1512), sobresalió por su poder dialéctico. «En la actualidad, continúa diciendo Erasmo,

10 Ibid.: p. 610. Acerca de la difusión de Vives en Europa, cfr. Enrique González, o. c.. p. 42ss. Sobre la difusión de Vives en España, cfr. o.c., p. 54ss.

11 José Jiménez Delgado, o.c., p. 144.

12 A raíz de un reciente viaje a París, Vives cuenta a Erasmo el cambio que ha observado en aquella Universidad. No fue mal recibido por los profesores; a pesar de las duras críticas de que habían sido objeto en su obra Adiersus pseudodialecticos. Acerca de los españoles allí presentes, dice que «impulsaban orientaciones más importantes a los estudios». Cf. o.c.. p. 186-189. 
Vives está completamente consagrado a disciplinas no tan pendencieras». El propio Luis Vives se alegra de haber sabido rectificar a tiempo:

\begin{abstract}
«Creí, pues, que no debía retrasar por más tiempo hacerte sabedor de lo que me reclaman tiempo atrás los hombres doctos y muy amigos míos. Efectivamente, cuando trato con ellos amigablemente y tocamos el tema del Renacimiento literario y al mismo tiempo, junto con los que forman el seminario de todas las mejores disciplinas, nos ocupamos con preferencia de esta materia, a la vez que nos alegramos de nuestro siglo, ellos suelen lamentarse sobremanera de que en París, de donde debería difundirse el brillo de toda erudición, algunos hombres se afanen a su execrable barbarie y con ella a ciertas manifestaciones monstruosas de sus disciplinas, como los sofismas, que ellos así las llaman, que es lo más insustancial y necio que se puede dar». ${ }^{13}$
\end{abstract}

La crítica de Vives no va contra la escolástica en general, cosa que sí hicieron otros humanistas, entre ellos Erasmo, sino contra los «pseudo-dialécticos», es decir, contra aquellos escolásticos que convertían la ciencia de la dialéctica en una logomaquia.

De los maestros que Luis Vives tuvo en París, deja a salvo de sus críticas al aragonés Gaspar Lax, al cual continuó visitando durante sus viajes a París. En carta a su amigo Juan Fort, Vives le recomienda lo siguiente: «Añade también algo de las cavilaciones de Suiseto y algunos temas ingeniosos de Gaspar Lax sobre dialéctica». ${ }^{+t}$

¿Tuvo repercusión en España la dura crítica de Vives a la lógica escolástico-terminista? Sí, pero en sentido negativo, porque provocó una reacción en contra suya por parte de muchos filósofos escolásticos que se sintieron aludidos por las descalificaciones de Vives contra los «frailes», causantes, según él, de la corrupción de la dialéctica. ${ }^{15}$

La Lógica Moderna que se enseñaba en París fue materialmente trasportada a España con ocasión de la fundación de la Universidad de Alcalá a comienzo del siglo XVI (1508). El Plan de Estudios de esta Universidad estaba elaborado, por deseo de Cisneros, «a imagen de la Universidad parisiense». ${ }^{16}$ Algunos profesores españoles que enseñaban en París (Miguel Pardo, Pedro Sánchez Ciruelo) fueron llamados por Cisneros para ocupar las primeras cáte-

13 Prólogo de Erasmo a Declamaciones Silanas de Luis Vives. Madrid O.C. I. Aguilar. 1947. p. 704. Cf. José Jiménez Delgado, o.c., p. 143. Tomás Moro, en carta a Erasmo, alaba la obra Adiersus pseudodialecticos de Vives. Cfr. José Jiménez, o.c..: p. 183.

14 Carta de Vives a Juan Fort. Cfr. José Jiménez Delgado, Ibid., p. 109.

15 Vives, en su viaje a París, pudo comprobar cómo la mayoría de los profesores habían recibido con serenidad sus críticas y cómo habían dado una orientación más realista a su filosofía. En España sucedió todo lo contrario. Vives culpa de esa animosidad contra él y contra Erasmo a los frailes, a los que trata con bastante desdén: «Los frailes, no pudiendo soportar esto, sino que por la lectura de un solo librejo iban a verse precipitados de lo alto de su dignidad, de sus riquezas, de su predominio y de tan grandes bienes, se lanzaron contra su autor...) (Carta de Vives a Cranevelt, 13 de junio de 1527). Cf. José Jiménez Delgado, o.c., p. 468. Sobre la postura de Juan Luis Vives en el ámbito de la lógica humanista, el padre Vicente Muñoz la ha estudiado en sus numerosos escritos sobre la lógica medieval y humanista. Una buena síntesis puede verse en «Nominalismo, Lógica y Humanismo» dentro de la obra colectiva El Erasmismo en España, Sociedad Menéndez Pelayo, Santander, 1986, pp. 108-174.

16 Juan Urriza, La preclara Facultad de Artes y. Filosofía de Alcalá de Henares, Madrid, 1942. pp. 348-355. 
dras. Domingo Soto criticó la imitación del modelo parisiense calificando a la Universidad de Alcalá de «la mona de París».17

En la Universidad de Salamanca sucedió algo parecido. Al darse cuenta de que las aulas se quedaban vacías porque los alumnos preferían la enseñanza de la lógica moderna o terminista que se impartía en Alcalá, el Claustro decidió establecer

«Cátedras nominales de lógica»; y para ello se enviaron «ciertos hombres doctos a París para que con grandes salarios truxesen los más principales y famosos hombres que de los nominales hallasen» para lógica, filosofía y teología nominalistas «por el modo y forma que en aquellos tiempos en la Universidad de París se leían».18

En torno al año 1515 comenzó a enseñar lógica moderna o nominalista en la Universidad de Salamanca Juan Martínez Silíceo. El entusiasmo nominalista aparecía en Alcalá y en Salamanca en el momento crepuscular de la Dialéctica medieval de signo terminista.

La implantación del «modo parisiense» en España chocó con la oposición de Hernando Alonso de Herrera, primer maestro de Retórica y de Gramática en la Universidad de Alcalá y, posteriormente, de Retórica en la de Salamanca, el cual escribió un opúsculo, dedicado a Cisneros, con el título: Disputa de ocho levadas contra Aristótil y sus secuaces (Salamanca, 1517), ${ }^{19}$ dos años antes de que Luis Vives publicase su opúsculo Adversus pseudo-dialecticos. Hernando Alonso de Herrera expone en este opúsculo ideas plenamente renacentistas, como: la renovación de las buenas artes mediante la vuelta a los clásicos, y la crítica despiadada contra la dialéctica nominalista parisiense, justamente en nombre de Aristóteles. A juicio de Alonso de Herrera:

«lo que menos hoy hacen los maestros de lógica, es enseñar lógica. Jarretan los ingenios y estragan los entenderes, que ni en lo natural ni moral, ni en Matemáticas o Teología seamos cuales debíamos... llevando el verdadero camino de las artes, y no el astroso... Ya los artistas se han tornado canonistas, que, en lugar de razones, arrojan textos y no afinan hasta lo vivo la verdad con balanza de razones infalibles. El día de hoy, tan corrupta y confusamente se enseña todo esto, que mayor trabajo es conocer lo verdadero que aprenderlo...». ${ }^{20}$

La crítica de Hernando Alonso de Herrera a los nominalistas se basaba en la separación que los nominalistas habían establecido entre las tres ramas el Trivium, desligando la Dialéctica de la Gramática y de la Retórica, y convirtiendo a la primera en un saber propio y

17 Domingo Soto, Prólogo a la segunda edición de las Summulae, Salamanca, 1543.

18 Libro $5^{\circ}$ de Claustros del Archivo Universitario Salmantino, fols. 133v-134. Cfr. Vicente Muñoz Delgado, La lógica nominalista en la Universidad de Salamanca, 1500-1530. Madrid, 1964, pp. 82-88.

19 Gabriel González. «La polémica antidialéctica de Alonso de Herrera y Luis Vives» en Curadernos Salmantinos de Filosofía, XI (1984) p. 355.

20 Alonso Herrera, Disputa de ocho levadas contra Aristótil y sus secuaces, Ed. de Adolfo Bonilla y San Martín, en Revue Hispanique, L (1920), p. 171ss. 
esencialmente formal. Como reacción a tanto logicismo de los escolásticos, la lógica humanista propugnó un retorno a la dialéctica de Aristóteles, lo cual implicaba volver a la unión de gramática, retórica y dialéctica; es decir, a la unión de la lengua con la realidad. Volver a la lengua común convirtiéndola nuevamente en vehículo de conocimiento universal. ${ }^{21}$

Hasta la segunda mitad del siglo XVI no tuvo entrada en la Universidad de Salamanca la lógica humanística. Hacia 1557 empezó Cardillo de Villalpando a criticar las doctrinas lógicas del periodo anterior, intentando armonizar la lógica de Aristóteles con la lógica de Rudolfo Agricola, triunfante esta última desde hacía medio siglo en las Univerdades europeas, incluida la de París. El mismo año de la muerte en Salamanca del lógico nominalista Pedro Sánchez Ciruelo, condiscípulo de Vives en París, Narciso Gregori mandó imprimir en Burgos (1554) la obra de Rudolfo Agrícola De Inventione Dialectica, para remediar a la que él califica de «enseñanza degradada de la lógica de Salamanca». A partir de esta fecha, son constantes las críticas a la enseñanza de la filosofía según el antiguo «modo parisiense», coincidiendo con las críticas que Luis Vives había hecho treinta y cinco años antes. Francisco Sánchez de las Brozas (el Brocense) fue un típico ejemplo de esta crítica implacable.

Al final, los ideales renacentistas acabaron desplazando de la Universidad española a la lógica terminista, aunque aquellos ideales no dieron en España los frutos cosechados en otros países europeos.

\section{CONTRA LOS «PSEUDO-DIALÉCTICOS»}

Cerca de cuatro años pasó Juan Luis Vives (1509-12) asistiendo a las aulas de los Colegios parisienses de Lemoine y Montagu. Aquí tuvo la ocasión de conocer las principales tendencias filosóficas de la ciudad del Sena: la lógica «terminista, la interpretación humanista de los textos aristotélicos y los movimientos de reforma espiritual. Terminada su estancia en esta ciudad Vives se trasladó a vivir a Lovaina, en cuyo Colegio Trilingüe estudió y enseñó. De su contacto con los ambientes humanísticos, volcados sobre los problemas pedagógicos y de la lectura de la obra de Rudolfo Agricola De inventione dialectica (Cononia, 1523), brotó su crítica implacable a los que él califica "pseudo-dialécticos», es decir, modernos sofistas. Juan Luis Vives no era el primero en criticar a dialécticos y escolásticos por sus excesos verbales y su mal latín; antes que él habían hecho lo mismo Dante, Leonardo Bruni, Lorenzo Valla, Desiderio Erasmo y otros. La diferencia entre éstos y Juan Luis Vives está en que la crítica del humanista valenciamo va acompañada de un programa de reforma para la enseñanza de la lógica y de la filosofía.

21 Luis Vives, Adiersus pseudodialecticos (1520): «Los pseudodialécticos se fabrican una lengua nueva que entienden ellos solos». «Decidme, por favor, ¿De qué lengua es esta Dialéctica vuestra?, ¿Del francés?, ¿Del español?. ¿Del gótico?. ¿Del vándalo? Pues ciertamente no es el latín» (p.301). Aristóteles «no definió en toda su Dialéctica la más mínima regla que no estuviera de acuerdo con el sentido mismo de la lengua griega tal como la usaban los hombres instruidos, los niños, las mujeres, en una palabra, el pueblo entero». Cfr. O.C., II, pp. 294 ss. 
La «barbarie» de los escolásticos, escribe Vives, consiste en que han fabricado un leguaje latino nuevo que sólo ellos entienden, de tal forma que ese lenguaje ha dejado de ser un vehículo de comunicación entre personas; más aún, al enseñar en las escuelas un latín distinto, están privando a los estudiantes de entrar en contacto con las virtudes literarias, morales y científicas que atesora la auténtica lengua latina, la que cultivaron los escritores clásicos romanos y los Padres de la primera Iglesia. A juicio de los humanistas esto es una deshumanización, una pérdida de los valores humanos de la cultura clásica.

De aquí arranca la crítica juvenil de Vives a los escolásticos y pseudo-dialécticos. Los primeros, escribe, han corrompido la lengua latina, y los segundos han convertido la lógica en un lenguaje supertecnificado, reducido a sentido formal, sin referencia a la realidad de las cosas. La Dialéctica o lógica, tal como la practican los nominalistas y terministas no se parece ya a la Dialéctica aristotélica, porque, mientras ésta es un instrumento al servicio de la ciencia, aquella se ha constituido en un saber propio, desligada de las dos artes con las que siempre había estado unida: la gramática y la retórica."2 Para los humanistas, la ruptura del Trivilum va contra la naturaleza misma de la lengua viva, cuya misión principal es la de servir de común entendimiento entre las personas. Pero, los modernos sofistas o dialécticos han tecnificado de tal forma la estructura formal de la dialéctica que sólo ellos la entienden; esa dialéctica no dice relación a la experiencia natural y su sintaxis no es la sintaxis que corresponde al uso común de una lengua.

Juan Luis Vives no está en contra de la Dialéctica, pues sabe bien que san Agustín y otros Padres de la Iglesia la usaron en sus escritos y sermones; Vives está contra el mal uso de la misma. El filósofo valenciano lamenta que muchos filósofos y teólogos escolasticos, llevados por esta moda, sometan los problemas teológicos y filosóficos a la tiranía del nuevo lenguaje:

«...frailes que se dicen teólogos, y que piensan que nada puede decirse con agudeza si no va sazonado con aquel amarguísimo condimento y aliñado con aquella hórrida o inculta barbarie y mechado con sosas impertinencias sofistas».23

Sin embargo, cuando se les enseña a estos pseudo-sofistas que san agustín usaba la Dialéctica para escribir sobre la Trinidad sin acudir a la «distribución completa e incompleta, a los supuestos mediatos e inmediatos», ${ }^{2+}$ quedan enormemente extrañados. Lo mismo les sucede al constatar que para tratar del Bautismo, tampoco acude a los distingos que emplea la sofistería escolástica:

«Aquel que se espantó de no hallar en san Agustín tales lindezas, luego al punto dejó de espantarse y, sutil y certeramente, descubrió la causa por la cual Agustín no enseñó eso. El motivo fue porque san Agustín escribió en lengua latina; y eso, en cambio, no

22 La dialéctica es arte que no se aprende por ella misma, sino para que preste su concurso y sus servicios, como quien dice, a las artes restantes». Cfr. O.C..II. p. 308.

23 Ibid., p. 305.

24 Ibid., p. 305. 
puede expresarse más que en una bárbara y bronca algarabía... A esa estultísima y pestífera opinión se sumaron algunos que están persuadidos que así la filosofía, como la teología, como las restantes disciplinas no pueden enseñarse en lenguaje correcto y castizo».25

Así, pues, para los humanistas la lengua latina, tomada en su uso común y en la forma como la usaron los clásicos, es una fuente de saber y el medio más adecuado para expresarlo. Como reacción a esta defensa del uso común de la lengua que hacían los humanistas, los nominalistas y terministas comenzaron a llamarlos despectivamente «gramáticos», porque, en teoría, la gramática es un saber inferior a la dialéctica.

«Si alguna cosa se escribió con un relativo esmero y pulcritud, sea cual fuere su argumento, a ello (tan necios y estúpidos son) no le llaman filosofía, ni teología, ni derecho, ni medicina, sino pura y simplemente gramática; dice que los Deberes o las Paradojas o las Cuestiones tusculanas o Académicas de Cicerón no son más que gramática. Sólo lo que ellos hacen, porque no está sujeto a las leyes gramaticales y manchado con todas las sordideces de dicción imaginables no es gramática. Y yo digo que en realidad es así, pues aquello ni es gramática ni es nada. Escoto, Ocham, Pablo Véneto, Hentisber, Adán Godam, Bochim Kam entienden ellos que no son gramáticos, sino filósofos y teólogos. Y, en cambio, Cicerón, Plinio, San Jerónimo, San Ambrosio, gramáticos son fuera de la escuela; ocúpense de ellos los gramáticos. ¿Cómo puede ser, se preguntan ellos, que en aquel terso y elegante estilo, no ya en latín, sino en alguna lengua autóctona, no depravada ni sucia, puedan enseñarse la filosofía, la teología y las restantes artes? ¿Puede decirse desatino mayor? Yo, a ese error, no por la bondad de Dios y no con salud mala viviera diez años más, lo raeré de su cabeza no con argumentos, sino con efectividades». ${ }^{26}$

No se puede negar la parte de razón que encierra la crítica de Juan Luis Vives a la escolástica y al tecnicismo lingüístico que empleaban los escolásticos. Pero, también hay que añadir que su crítica a la dialéctica terminista encierra, probablemente, un grave desconocimiento del sentido filosófico de esta clase de dialéctica. En efecto, la dialéctica terminista se basa en la ruptura del binomio «verba et res», superando el isomorfismo aristotélico entre pensamiento (verba) y cosas (res). En consecuencia, el Trivium pierde todo su sentido como saber unitario. Traducido esto a terminología terminista, significa que en la palabra podemos distinguir entre «significado» y «contenido significativo». La lógica moderna estudia lo primero, el significado, ya sea en sí mismo o dentro de la proposición. La diferencia con la lógica aristotélica es clara, pues mientras ésta no distingue entre cuestiones lingüísticas y ontológicas, los dialécticos nominalistas y terministas establecen dos dimensiones: la del significado (caballo) y la del contenido significativo (este caballo). 
Lo mismo sucede con las proposiciones. Para los realistas, el valor significativo de las proposiciones siempre tiene carácter cualitativo (depende de las cosas y de la intención del sujeto), mientras que para los terministas, la proposición puede reducirse a elementos cuantitativos, de tipo numérico o simbólico. Según esto, la dialéctica se constituye en un lenguaje propio, con su terminología y con sus reglas específicas. Este lenguaje es considerado como el único lenguaje autorizado en filosofía para hablar de la verdad. De ahí que, en el siglo XVII, Leibniz quisiera fundar la filosofía en el análisis lógico de la lengua, elaborando para ello una Characteristica universalis o lengua simbólica, ideal, con reglas precisas de transformación y definición (calculus ratiocinator y ars combinatoria). ${ }^{27}$

No parece que Juan Luis Vives hubiera tenido en cuenta este avance de la lógica en sus críticas a los pseudo-dialécticos. El padre Vicente Muñoz cree que cuando Vives escribió Adversus pseudo-dialecticos (1519), desconocía el alcance científico de la lógica terminista. El humanista valenciano se mueve guiado por un interés pedagógico y por una concepción de la verdad de tipo histórico. Los humanistas admiran el pasado y veneran todo lo que es natural, porque dan por supuesto que la verdad anda de forma difusa desde que Dios, «in illo tempore», la depositó en el mundo. Por eso tiene tanta importancia para ellos buscar la verdad en la historia, y cuanto más remota sea ésta mejor. Si las lenguas vivas son fieles depósitos de la verdad, las lenguas cultas, como el griego y el latín, lo son de un modo especial. Para los humanistas, la lengua latina es superior a la griega porque atesora la verdad pagana (autores clásicos) y la verdad cristiana (san Agustín y otros Santos Padres). A juicio de los humanistas, la lengua latina reune casi todo el saber de la antigüedad, y, además, es una escuela de formación literaria, moral y religiosa.

La reforma del saber, objetivo buscado por los humanistas, debe comenzar por el restablecimiento de la lengua latina en su sentido más natural y genuino. Está probado que la jerga latina creada por escolásticos y pseudo-dialécticos no hace cultas a las personas; al contrario, las embrutece y las aleja de la fuente de donde brota el saber; el estilo y el gusto moral. En cambio, la lectura de los autores clásicos trasmite a los lectores valores estéticos y morales. Frente a la Dialéctica terminista, sinónimo de deformación de la realidad, los humanistas abogan por la recuperación de la Gramática, expresión del uso común de la lengua. A la «barbarie» de los escolásticos, los humanistas oponen la «elegancia» del latín clásico.

\section{JUAN LUIS VIVES Y LA LÓGICA HUMANÍSTICA}

El opúsculo de Vives contra los pseudo-dialécticos recoge el ambiente que se vivía en los círculos humanísticos contra escolásticos y lógicos terministas. Eran los años en que la obra de Rudolfo Agrícola se abría paso en todas las Universidades. Sin embargo, la pequeña obra de

27 González G., Polémica antidialéctica de Alonso de Herrera y Luis Vives, ayer y hoy» en Cuadernos Salmantinos de Filosofía. XI (1984), 361. 
Juan Luis Vives tiene algo especial que explica por qué tuvo tan buena acogida entre los humanistas: la sinceridad con que se expresa el joven filósofo:

«Yo no obligo a nadie; ni aun cuando quisiera, yo podría. Aviso y digo, como parece bien en un filósofo, lo que siento con toda libertad». ${ }^{28}$

Tras la publicación de esta obra, Juan Luis Vives se tomó un largo periodo de reflexión en tierras inglesas (1519-31), durante el cual leyó a Rudolfo Agrícola (De inventione dialectica), a Melanchton (Dialectica) y a Juan Sturn (varios escritos sobre lógica). En Inglaterra estuvo en permanente contacto con erasmistas y humanistas británicos, como Tomás Moro y Colet, y con lo más granado de la Corte de Enrique VIII y de la cultura inglesa. En esos momentos Inglaterra pasaba por un periodo de intensa vida política, social y cultural, lo cual contribuyó a que Vives madurase las ideas humanísticas que había traído del Continente.

Bajo el influjo del humanismo inglés, Juan Luis Vives escribió su obra filosófica de madurez: De tradendis disciplinis (1531), cuya primera parte comienza hablando de la «corrupción de las artes en general», una ampliación de los temas tratados anteriormente, pero expuestos ahora desde una visión filosófica más completa. A continuación se detiene en el análisis de la mente humana (sensación, memoria, imaginación), la cual es, según Vives, lo mejor de la acción creadora de Dios. Semejante don obliga al hombre a desarrollarla y a perfeccionarla. Por esta razón, la erudición (eruditio) es, al mismo tiempo que una necesidad, una obligación moral y religiosa del hombre (pietas). No cabe, por tanto, oposición entre razón y fe, entre naturaleza y gracia, por lo menos en teoría. Si en la práctica no sucede así, será debido al propio hombre, que no sabe controlar sus resortes psicológicos e intelectuales. Por esto es $\tan$ importante emprender una reforma de los métodos educativos, de las técnicas de aprendizaje y de los saberes.

Juan Luis Vives pone entre paréntesis las tadicionales especulaciones metafísicas y teológicas sobre el «alma y la vida» humanas y se centra en el análisis de las" «estructuras» y «tendencias» de la mente, en sí mismas y en su relación con la experiencia. Este análisis es de gran importancia para su concepción de la lógica dialéctica, a la que despoja de cualquier apriorismo para que pueda servir de guía en el conocimiento de la realidad.

\subsection{La Gramática}

Para el humanista valenciano, la corrupción de la lengua es efecto de la separación establecida por los pseudo-dialécticos entre «verba et res», la cual da lugar al surgimiento de un lenguaje nuevo, esencialmente formal, que sirve de base a la lógica nominalista. Los humanistas consideran que la pérdida del sentido natural del lenguaje atenta contra el ser mismo de la persona, que es por naturaleza un ser dialógico y social. Las palabras crean puentes de comunicación entre las personas para vivir civilizadamente. Las palabras no son, por tanto, meros instrumentos de comunicación, sino aquello que hace al hombre ser tal, porque median-

28 Juan Luis Vives. O.C., II, p. 341. 
te el diálogo las personas organizan la sociedad, se desarrollan intelectualmente y crecen moral y religiosamente.

Los antiguos tratadistas aplicaron la palabra «gramática» a todo lo relacionado con el estudio de la lengua, es decir, al conjunto de las tres artes liberales del Trivium:

«Por unánime consentimiento de los escritores antiguos, tres son las artes que tratan del lenguaje; a saber: la gramática que indica lo que se dice y la manera como se dice; la retórica, que se refiere al ornato y acicalamiento; la dialéctica, que atañe a los argumentos y a la probabilidad. La gramática contiene aquello que los antiguos quieren enseñar; la dialéctica, lo que quieren probar, y la retórica, los afectos que quieren mover... Ahora mismo hablaré de la gramática. Aplícase a las letras, ese vocablo griego gramática, que Quintiliano transformó en literatura al pasarlo al latín, voz legítima y propia, pero que no tuvo demasiada suerte en su admisión».9

La gramática es un arte, un saber que abre la puerta al filosofar. Por eso dice Vives que, quienes emplean la palabra «gramático» en sentido despectivo, olvidan que la verdad y la falsedad son conceptos sacados del uso común del lenguaje, y que los lenguajes formales creados por los nominalistas son posteriores a la existencia del lenguaje común. La lengua proporciona los primeros conocimientos de las cosas, y éstos dependen del buen uso que se haga de la lengua.

\subsection{La dialéctica}

El proyecto de reforma del saber que presenta Juan Luis Vives en el libro De las Disciplinas se basa en el uso de la lengua común: se comienza por la gramática o las tres artes liberales, se continúa con el estudio de la naturaleza y se concluye con la metafísica. A continuación, el humanista valenciano enseña todo lo relacionado con la forma de descubrir argumentos y de presentar lo asuntos tratados. Estas dos actividades reciben el nombre de Dialéctica:

«Dos son, pues, las artes que establecieron referentes al lenguaje, a saber: la dialéctica, que Cicerón llama arte de discurrir, y Aristóteles le da el nombre de lógica, y la retórica, que es el arte de hablar. De estas dos artes, la primera concreta el argumento con unos como puntos pocos y breves, la segunda, la amplifica y acomoda a las causas judicial, deliberativa, demostrativa. Por eso Zenón decía con gráfica imagen que la dialéctica era semejante a la mano cerrada en forma de puño, y la retórica, a la misma mano con toda la palma abierta. En ese a manera de edificio del lenguaje, la gramática corta la madera y extrae los sillares; la dialéctica construye la casa, y la retórica funda la ciudad. La gramática avanza hasta la conjunción de las palabras; la dialéctica, hasta la argumentación; la retórica, hasta el lenguaje, más exactamente, hasta el discurso». ${ }^{30}$

29 Ibid., p. 399.

30 Ibid., p. 425. 
Aunque, frecuentemente se usan de modo indistinto las palabras «lógica» y« dialéctica», no se olvide que Aristóteles otorgó a cada una de ellas un ámbito de significación diferente: la lógica equivale a silogismo o razonamiento deductivo construido con premisas ciertas y verdaderas, mientras que la dialéctica es un razocinio con premisas sólo probables. Por eso es llamada la dialéctica lógica imperfecta o lógica aplicada, porque sirve para argumentar dentro del ámbito de lo probable, que es todo lo concerniente al conocimiento de las cosas humanas. La lógica, en cambio, pertenece al orden de los principios formales.

De ahí deriva ese «escepticismo» que profesan los humanistas sobre el conocimiento de todo lo relacionado con la vida del hombre. Reconocen la tendencia del hombre al conocimiento de la verdad pero, a la vez, afirman la imposibilidad de aprehenderla de una manera total. A una proposición referida al dominio de lo humano podemos dar nuestro asentimiento afirmativo, negativo o dudar de ella, pero nunca podremos concederle certeza absoluta. Nos movemos, pues, dentro de lo probable:

«La mente humana, que es la facultad para conocer la verdad, tiene cierta simpatía y parentesco con aquellas verdades primordiales, que son como la semilla de donde nacen todas las verdades restantes, que reciben el nombre de anticipaciones y formaciones, llamadas catalepsis por los griegos. Ahí tuvo su origen la opinión de Platón, a saber, que nosotros no aprendemos, sino que recordamos... Pero esto, a la verdad, no más que al modo que los tienen noticias de los colores antes de que del útero materno salgan a la luz; tienen la potencia, pero no el acto». ${ }^{31}$

Juan Luis Vives asume el sentido aristotélico de la dialéctica, pero liberada de las implicaciones metafísicas que el Estagirita le confiere en algunos pasajes de su obra:

«Por otra parte, séame permitido decir que la trató, además de oscura y prolijamente, según su costumbre, con escaso acomodo a la práctica o de hallar argumentos o de juzgar argumentaciones. No hay persona nacida que, por más que haya leído y meditado de un extremo al otro la lógica de Aristóteles, se persuada que tiene un instrumento que le proporcione el rápido hallazgo de argumentos de cualquier materia puesta a disertación. Su primer libro, con el que, a la misma puerta de ingreso, se daba de bruces, es el de las Categorias, que suena (a) predicamentos en romance, y que Quintiliano interpreta por elementos, y Mariano Capella, predicaciones. Su conocimiento y tratado pertenece a la facultad más alta: a la filosofía primera».3.2

\subsection{La invención de los argumentos}

El razonamiento dialéctico busca la verdad, aunque sabe que sólo puede aprehenderla relativamente, porque sus elementos de credibilidad, las premisas, se fundan en la información trasmitida por los sentidos o en otras premisas que no son absolutamente ciertas. Por esta

31 Ibid.., p. 979.

32 Ibid... p. 427-28. 
razón, Aristóteles, Cicerón y muchos humanistas han elaborado argumentos que, aplicados a los casos concretos, proporcionan el máximo grado de probabilidad en los juicios. No se trata de tomar al pie de la letra tales argumentos, pero sí de tenerlos en cuenta como modelos de argumentación:

«Todos los que partiendo de cosas claras y ciertas se lanzan a la investigación de lo que es cierto y obscuro usan documentos inéditos... El jurisconsulto, el médico, el geómetra, el retórico que examinan y buscan la esencia, los accidentes, las causas, los efectos... Todo ello pone a la inmediata disposición de mentes experimentadas la penetración y la claridad del intelecto». ${ }^{33}$

Como quiera que no resulta fácil a una persona particular encontrar tales modos de argumentar, Vives propone, siguiendo la tradición clásica, la creación de un arte de hallar argumentos, que pueda ser estudiado y aplicado. Cicerón dice que fue Aristóteles el inventor de este arte: los Tópicos o «lugares comunes».

«Cada cosa, pues, está colocada y ordenada como en apartados y casillas a quien, con nombre muy apropiado, llamaron lugares, denominación que plugo a Aristóteles, inventor de esa facultad, si hemos de dar crédito a Cicerón. Lugar quiere decir el instrumento mediante el cual tenemos un atisbo de la razón probable. Estos nombres son como las etiquetas que ponen en sus tarros los farmacéuticos y los drogueros, que les advierten lo que contienen cada vasija o cápsula, por no tener que revolverlas todas cuando se necesita una sola». ${ }^{3+}$

\subsection{El juicio}

Comienza Juan Luis Vives explicando la naturaleza de las palabras, la estructura de las oraciones y la formación de las proposiciones, sobre las que recae la verdad o falsedad. Cuando las proposiciones son encadenadas entre sí forman argumentos: Acerca de las proposiciones, Vives señala que no es posible determinar si son falsas o verdaderas; para salir de dudas recomienda acudir a una persona experta en la materia:

«Para discernir cuál enunciación es verdadera y cuál falsa, no existe regla fija, sino el criterio de cada cual en la materia de su competencia y en lo que atañe a la vida común, el del varón prudente, muy práctico en los negocios y curtido por una larga experiencia, dotado copiosamente de sentido común y de muy avisada inteligencia».35

A pesar de estas limitaciones, Juan Luis Vives quiere ofrecer un instrumento que capacite a cada uno para averiguar cuándo una proposición es verdadera o falsa:

33 Fernández Santamaría. J.A., Juan Luis Vives. Escepticismo y prudencia en el Renaciniento. Universidad de Salamanca, 1990, p. 147.

34 Juan Luis Vives, O.C. II, p. 982.

35 Ibid., p. 1019. 
«Esto no embargante, vamos a entregar un instrumento, gracias al cual, cada uno en su profesión respectiva, tras un concienzudo examen de las cosas, pueda inquirir en los enunciados lo que es verdadero y lo que es falso». ${ }^{36}$

Juan Luis Vives dedica el libro segundo de la Censura de la verdad en la enunciación a la argumentación. Para que pueda darse ésta es preciso que los argumentos hayan sido bien elegidos y que estén dispuestos de manera ordenada:

«Argumento es la conexión de los enunciados, de forma que parezca que lo anterior se sigue y, en cierto modo, nace de lo posterior; y que guarda con él una cuasi necesaria coherencia. Un hombre discurre, luego ejercita la razón. Lo primero llámase antecedente, razón, argumento, premisa; lo posterior llámase siguiente, consiguiente, intención, ilación; todo ello para Cicerón es conclusión. Su nombre corriente es consecuencia». ${ }^{37}$

Los métodos más usados para establecer conexiones entre los argumentos son: el entimema, el epiquerema, el ascenso o enunciación, el descenso, la comparación, el ejemplo, la inducción, la gradación, el sorites, el dilema y la antístrofe..$^{38}$ El entimema es un silogismo imperfecto («aquello que se usa para probar algo imperfecto»); la inducción o epagoge (a partir de experiencias singulares la mente llega a algo general); la gradación tiene lugar «cuando muchas cosas se toman de tal manera que lo segundo puede ser inferido de lo primero, lo tercero de lo segundo y así sucesivamente»; el sorites indica que dada la premisa no puede derivarse la conclusión a partir de una inferencia silogística única (un montón de trigo sigue siendo el mismo tanto si le quito un grano como si le añado uno más); el dilema significa que ante dos alternativas, el oponente queda atrapado aunque tome un camino u otro.

Sin embargo, «la verdadera, genuina y perfecta argumentación es el silogismo, que significa colección. Cicerón le da el nombre de raciocinación»:

«Silogismo es la comparación de dos con un tercero, de la cual nacen la relación de los dos entre sí, de forma que o se enlazan o se sueltan». ${ }^{39}$

El valor del silogismo reside en que de lo universal es posible inferir o bien lo universal o bien lo particular, «de la negación, la negación; de las afirmaciones, la afirmación». 


\section{CONCLUSIÓN}

Juan de Salisbury, filósofo del siglo XII, dejó escrita una aguda observación sobre el saber de su tiempo:

«todo se hacía nuevo; se innovaba la gramática, se transformaba la dialéctica, se despreciaba la retórica; y del seno mismo de la filosofía sacaban nuevas vías para el cuadrivio, después de haber eliminado las reglas anteriores». ${ }^{10}$

De los tres saberes del Trivio, la Dialéctica será la que alcance mayor desarrollo en los siglos posteriores. En las Facultades de Oxford y de París se desarrolló como ciencia autónoma y recibió el nombre de Lógica moderna, para que apareciera con claridad su diferencia respecto de la Dialéctica del Trivio y de la Lógica aristotélica. A partir del siglo XIV comenzó a ser llamada también Lógica nominalista y terminista.

Juan Luis Vives entró en contacto con la Lógica moderna siendo alumno del Colegio universitario de Monteagudo, bastión de las reformas escolásticas y religiosas emprendidas por John Mair y Noel Bède. Durante su permanencia en ese Colegio conoció las dos tendencias intelectuales que entonces estaban en litigio: la corriente formalista, representada por los maestros de la ciencia y de la lógica terminista (Antonio Coronel, Gaspar Lax, Juan Dolz, Fernando Enzinas y Juan Dullaert) y la corriente humanista (Jacques Lefèvre d'Etaples, Budé y Erasmo), que fue la que más influyó en el valenciano. Por esta razón, al terminar sus estudios en París, Juan Luis Vives eligió los Países Bajos, feudos del humanismo, para establecer su residencia. Las primeras obras publicadas por Juan Luis Vives muestran su decidida conversión a los ideales religiosos del humanismo erasmista (Triunfo de Jesucristo, 1514) y su deseo de contribuir a la reforma del saber, liberándolo del «vicio» formalista (Contra los pseudo-dialécticos, 1519).

La vuelta al estudio de las letras humanas, recomendada por Juan Luis Vives y los humanistas, no significa oposición a la ciencia moderna. Pocos filósofos de aquella época defendieron con tanto ahínco el primado de la experiencia como el humanista valenciano. Precisamente, la crítica de Vives a los escolásticos y a los filósofos terministas se funda en que todos ellos se alejan peligrosamente de la realidad, sustituyéndola por un formalismo lingüístico puramente convencional. No se trata, por tanto, de oposición sino de diferente planteamiento: los defensores del formalismo buscan un saber cuyas proposiciones sean verdaderas y ciertas, y esto sólo se puede dar dentro de un lenguaje esencialmente formal. Los humanistas, en cambio, se ocupan de cuestiones relacionadas con la vida del hombre en sociedad, en donde no caben respuestas absolutamente ciertas, sino acompañadas de más o menos probabilidad. Los primeros buscan hacer ciencia demostrativa, y por esa razón manejan los conceptos y los términos como si fueran realidades numéricas; los segundos no salen del uso común de las palabras y de sus posibilidades expresivas. 
La diferencia epistemológica entre escolásticos y humanistas dio lugar al distinto sentido que adquirió la palabra «dialéctica». Para los primeros la Dialéctica es arte de la razón, y para los segundos es arte de la argumentación (ars disserendi). Los escolásticos nominalistas y terministas consideran que en el silogismo o en cualquier otra clase de inferencia no debe entrar ni la gramática ni la retórica. Todo lo contrario de lo que piensan los humanistas, que ven en la gramática el fundamento del discurso.

Empirismo y escepticismo suelen ir siempre unidos. Esta actitud intelectual era muy corriente entre los humanistas. Juan Luis Vives afirma la tendencia natural del hombre al conocimiento de la verdad, tanto de las cosas naturales como de las realidades metafísicas; pero resulta difícil, por no decir imposible, que las personas puedan aprehender la verdad totalmente, teniendo que conformarse con una aproximación a la misma. El conocimiento humano abarca sólo el ámbito de lo probable. Este es el punto de partida de la Lógica humanista o de la Dialéctica retórica: el estudio de las proposiciones cuya evidencia es sólo probable o verosímil.

El arte de la Dialéctica se compone de dos partes: la invención y el juicio. Los humanistas toman de la tradición clásica (Aristóteles, Cicerón, Quintiliano) lo concerniente a la invención: una guía metodológica para el descubrimiento de argumentos sobre cualquier tema. Rudolfo Agricola denominó «lugares comunes» a estas pautas de nociones claves en las que están incluidas todas las posibles fuentes de información.

Juan Luis Vives dio a la invención carácter instrumental, desligándola de todo contenido categorial (un error cometido por Aristóteles, a juicio de Vives), y del uso que de ella venía haciendo la retórica. A juicio de Juan Luis Vives, la invención es una parte de la dialéctica, y tiene por objeto acumular evidencias en orden a conseguir cierto grado de persuasión que haga posible una elección libre y prudente. ${ }^{+1}$ Juan Luis Vives reconoce el valor del silogismo («la forma más perfecta de argumentación»), pero el problema está en saber descubrir premisas más exactas a partir de aquellas que el silogismo pone en marcha, para obtener mayor evidencia.

Jorge M. Ayala

San Antonio María Claret, 9

E-50005 ZARAGOZA 41 Noreña, C.G., «...los libros de Vives son la expresión de una concepción retórica de la lógica como dia-
léctica de la persuasión, arte del discurso y teoría de la comunicación humana», o.c., p. 322 . 